\title{
Sound velocities of bridgmanite from density of states determined by nuclear inelastic scattering and first-principles calculations
}

Catherine McCammon ${ }^{1 *}$, Razvan Caracas ${ }^{2}$, Konstantin Glazyrin ${ }^{3}$, Vasily Potapkin ${ }^{1}$, Anastasia Kantor ${ }^{1,4}$, Ryosuke Sinmyo ${ }^{1,6}$, Clemens Prescher ${ }^{1,7}$, Ilya Kupenko ${ }^{1,4,8}$, Aleksandr Chumakov ${ }^{4,5}$ and Leonid Dubrovinsky ${ }^{1}$

\begin{abstract}
Sound velocities of bridgmanite measured in the laboratory are a key to deciphering the composition of the lower mantle. Here, we report Debye sound velocities determined using nuclear inelastic scattering (NIS) for one majorite composition $\left(\mathrm{Mg}_{0.82} \mathrm{Fe}_{0.18} \mathrm{SiO}_{3}\right)$ and five bridgmanite compositions $\left(\mathrm{Mg}_{0.82} \mathrm{Fe}_{0.18} \mathrm{SiO}_{3}\right.$, $\mathrm{Mg}_{0.86} \mathrm{Fe}_{0.14} \mathrm{Si}_{0.98} \mathrm{Al}_{0.02} \mathrm{O}_{3}, \mathrm{Mg}_{0.88} \mathrm{Fe}_{0.12} \mathrm{SiO}_{3}, \mathrm{Mg}_{0.6} \mathrm{Fe}_{0.4} \mathrm{Si}_{0.63} \mathrm{Al}_{0.37} \mathrm{O}_{3}, \mathrm{Mg}_{0.83} \mathrm{Fe}_{0.15} \mathrm{Si}_{0.98} \mathrm{Al}_{0.04} \mathrm{O}_{3}$ ) measured in a diamond anvil cell at pressures up to $89 \mathrm{GPa}$ at room temperature. Debye sound velocities for majorite determined from NIS are consistent with literature data from Brillouin scattering and ultrasonics, while Debye sound velocities for bridgmanite are significantly lower than literature values from the same methods. We calculated partial and total density of states (DOS) for $\mathrm{MgSiO}_{3}$ and $\mathrm{FeSiO}_{3}$ bridgmanite using density functional theory and demonstrate that Debye sound velocities calculated from the reduced DOS using the same approach as for the experimental data (i.e., the limit of $D(E) / E^{2}$ as energy goes to zero) give the same sound velocities for each phase irrespective of which partial DOS is used. In addition, we show that Debye sound velocities calculated using this approach are consistent with values obtained from the calculation of the full elastic tensor. Comparison of the calculated DOS with the one obtained from NIS indicates that the experimental DOS has enhanced intensity at low energies that leads to a different slope of the DOS and hence a lower sound velocity. This effect is present in all of the bridgmanite samples examined in this study.
\end{abstract}

Keywords: Elasticity, Perovskite, Nuclear resonance, Sound velocity, Lower mantle, Density functional theory

\section{Background}

Insight into the accretion of the Earth and its subsequent differentiation can be gained through knowledge of the present-day Earth composition. The lower mantle in particular has been the focus of much attention as well as controversy, and questions such as how closely it approximates a chondritic composition have occupied geochemists for decades. Comparison of laboratory measurements of elastic wave velocities of lower mantle minerals with seismic data has played a crucial role in the discussion

\footnotetext{
* Correspondence: catherine.mccammon@uni-bayreuth.de

'Bayerisches Geoinstitut, Universität Bayreuth, Bayreuth 95440, Germany Full list of author information is available at the end of the article
}

starting with Birch (1952), and experimental techniques such as inelastic X-ray scattering (e.g., Fiquet et al. 2004), Brillouin scattering (e.g., Sinogeikin and Bass 2002; Jackson et al. 2005; Murakami et al. 2007; Murakami et al. 2008), ultrasonics (e.g., Irifune et al. 2008; Gwanmesia et al. 2009; Liu et al. 2015), and impulsive stimulated scattering (e.g., Crowhurst et al. 2008) have provided important results on transition zone and lower mantle minerals. In situ measurements are important, because some transitions (for example, spin transitions) are not quenchable, and may influence the elastic properties of iron-containing minerals.

Nuclear inelastic scattering (NIS) offers the attractive possibility to determine elastic wave velocities of iron- 
Table 1 Starting materials used for DAC experiments

\begin{tabular}{|c|c|c|c|c|c|c|c|c|c|}
\hline Sample & Phase & $x_{\mathrm{Fe}}$ & $x_{\mathrm{Al}}$ & $x_{M g}$ & $x_{\mathrm{Si}}$ & $\mathrm{Fe}^{3+} / \Sigma \mathrm{Fe}$ precursor & $\mathrm{Fe}^{3+} / \Sigma \mathrm{Fe}$ bridgmanite & ${ }^{57} \mathrm{Fe}$ enrichment & Ref \\
\hline U1219 & Majorite & $0.18(1)$ & 0 & $0.82(1)$ & $1.00(1)$ & $0.09(2)$ & $0.15-0.20$ & 0.9 & $a, b$ \\
\hline SL16 & Bridgmanite & $0.14(2)$ & $0.02(1)$ & $0.86(3)$ & $0.98(4)$ & - & $0.30(5)$ & 0.6 & c \\
\hline SL18 & Pyroxene & $0.12(1)$ & 0 & $0.88(2)$ & $1.00(1)$ & n.a. & $0.15(4)$ & 0.6 & \\
\hline S4850 & Bridgmanite & $0.40(3)$ & $0.37(2)$ & $0.60(3)$ & $0.63(3)$ & - & $0.80(5)$ & 0.9 & $f$ \\
\hline S4883 & Bridgmanite & $0.15(2)$ & $0.04(1)$ & $0.83(2)$ & $0.98(1)$ & - & $0.27(7)$ & 0.6 & g \\
\hline
\end{tabular}

a McCammon and Ross (2003); b McCammon et al. (2010); c Lauterbach et al. (2000); d Lauterbach (2000); e McCammon et al. (2008); f Potapkin et al. (2013); $\mathrm{g}$ this study

n.a. not analyzed

containing minerals in the laser-heated diamond anvil cell through direct measurement of the partial density of states (e.g., Sturhahn and Jackson 2007), and results for mantle minerals have already been reported for ferropericlase (Lin et al. 2006; Wicks et al. 2010; Chen et al. 2012; Sinmyo et al. 2014), orthoenstatite (Jackson et al. 2009) and post-perovskite (Mao et al. 2006). So far, however, no investigations using NIS have been carried out on the Earth's most abundant mineral that constitutes the bulk of the lower mantle, namely bridgmanite.

Computational studies provide an important complement to experimental measurements and allow a more extensive probe of parameter space. Methods have advanced substantially in recent years to enable densities and elastic wave velocities of candidate lower mantle assemblages to be calculated for the appropriate compositions at relevant pressure and temperature compositions (e.g., Wang et al. 2015 and references therein). Electronic transitions in iron present a challenge, however, and the apparent inconsistency between experimental and computational results on the stability of the intermediate spin state of $\mathrm{Fe}^{2+}$ in bridgmanite remains controversial (e.g., Stackhouse 2008; McCammon et al. 2013; Shukla et al. 2015). Nevertheless, a strong advantage of computations is the capability to calculate a wide range of properties including experimental observables based on vibrational density of states (DOS), for example infrared spectra of hydrous post-perovskite (Townsend et al. 2015). The combination of theoretical DOS calculations with experimental determinations using NIS provides a powerful new tool to understand the vibrational properties of iron-containing phases.

In this work, we present an experimental study using NIS to determine sound velocities of five different compositions of $(\mathrm{Mg}, \mathrm{Fe})(\mathrm{Si}, \mathrm{Al}) \mathrm{O}_{3}$ bridgmanite at pressures between 0 and $89 \mathrm{GPa}$ at room temperature, including a comparison with results for $(\mathrm{Mg}, \mathrm{Fe})(\mathrm{Si}, \mathrm{Al}) \mathrm{O}_{3}$ majorite with the same composition. We present a parallel theoretical study to calculate the DOS of two bridgmanite end-members $\left(\mathrm{MgSiO}_{3}\right.$ and $\left.\mathrm{FeSiO}_{3}\right)$ at comparable pressures that provides insight into the anomalous experimental results.
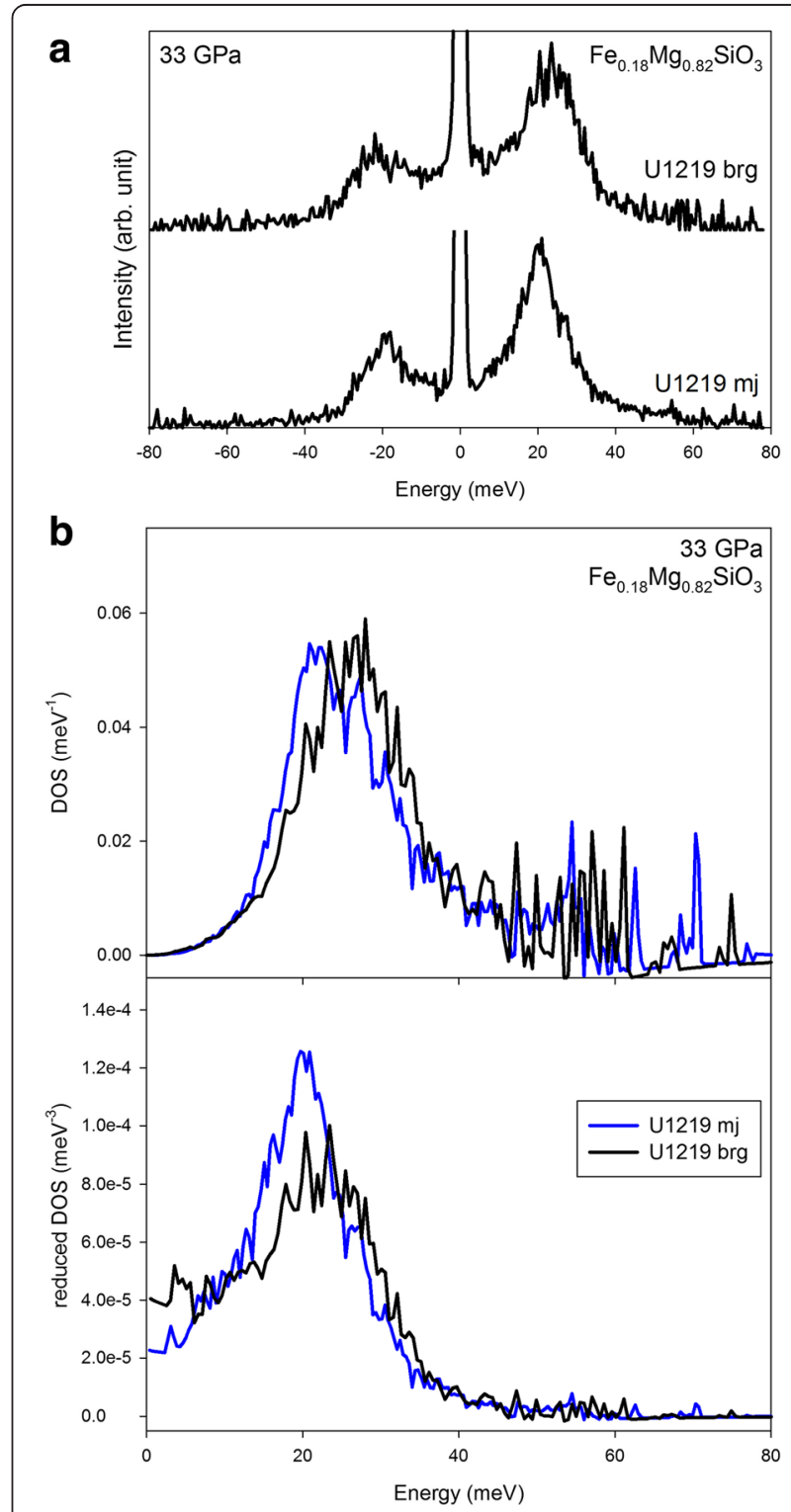

Fig. 1 Comparison of U1219 sample data for the majorite and bridgmanite phases at $33 \mathrm{GPa}$. a NIS spectra. b pDOS (upper) and reduced pDOS (lower). Majorite was measured first and then transformed to bridgmanite by laser heating, after which the NIS data for bridgmanite were collected 

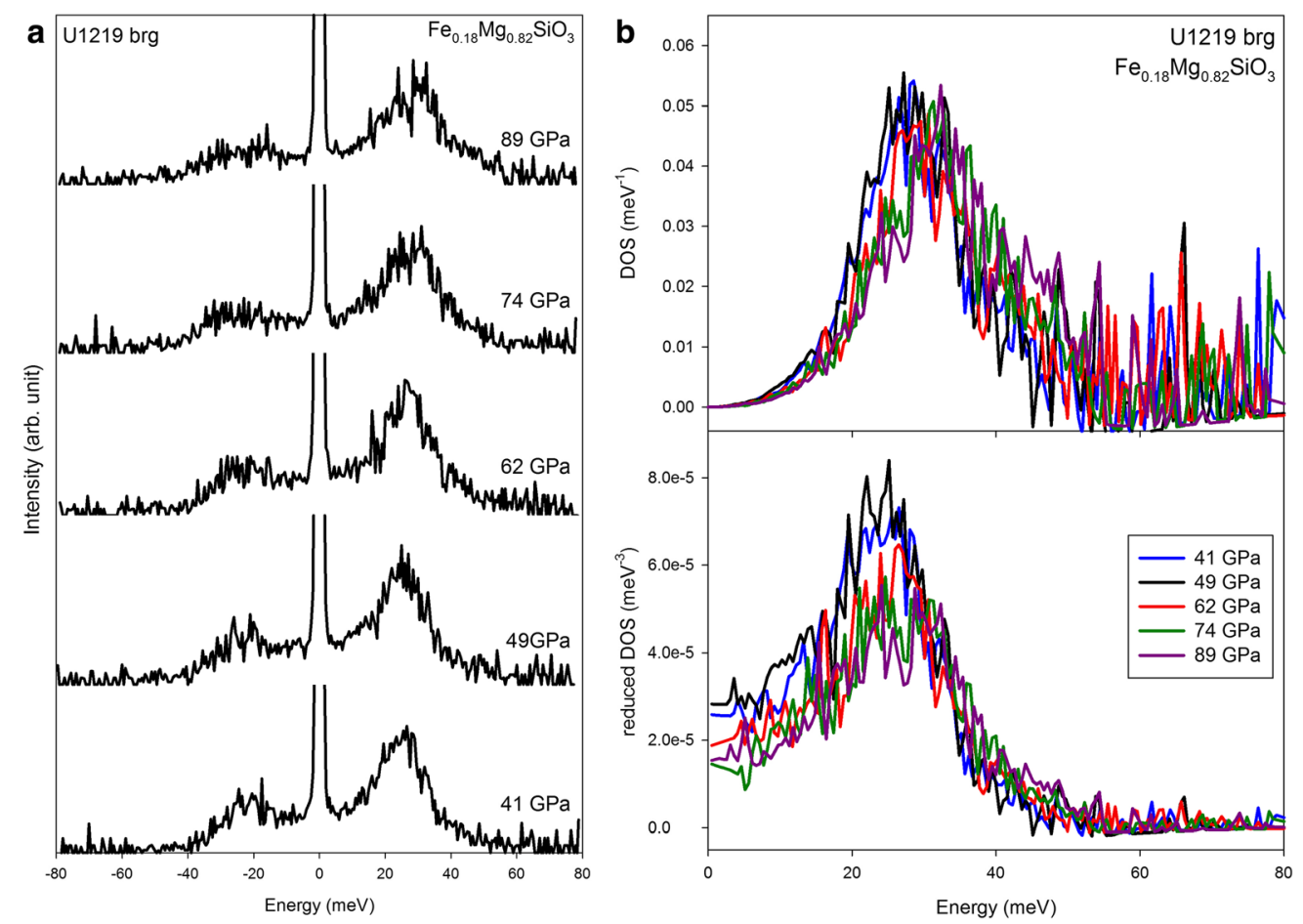

Fig. 2 Influence of pressure on U1219 bridgmanite. a NIS spectra. b pDOS (upper) and reduced pDOS (lower). Data were collected on compression during the same beamtime experiment and follow on from the spectra shown in Fig. 1
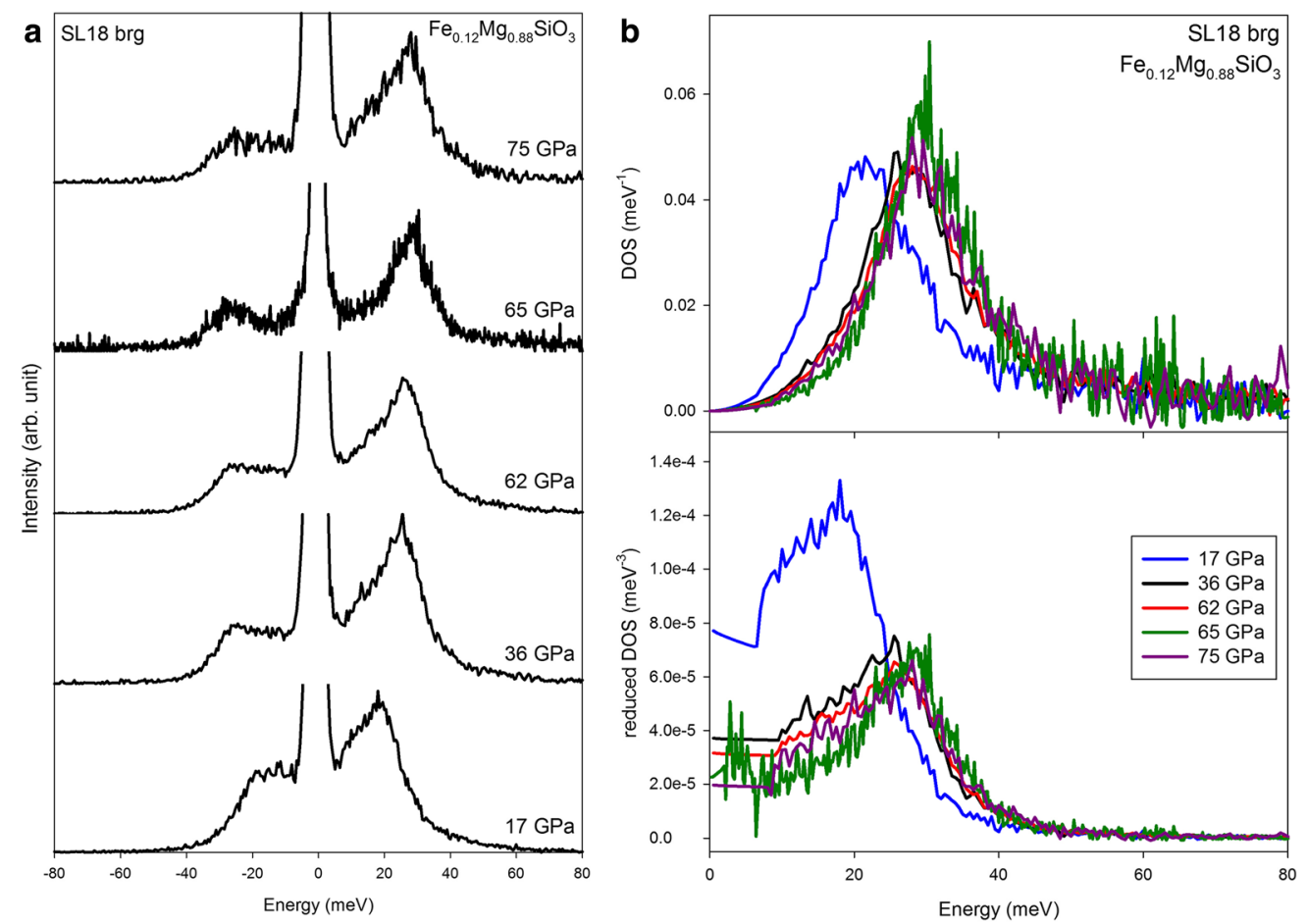

Fig. 3 Influence of pressure on SL18 bridgmanite. a Selected NIS spectra. b Selected pDOS (upper) and reduced pDOS (Iower). The SL18 pyroxene starting material was transformed to bridgmanite by laser heating in the DAC, and data were collected during three different beamtime experiments: \#1—17, 36, 62, and 75 GPa; \#2-50 GPa (not shown); and \#3-65 GPa 


\section{Methods}

The starting materials for the DAC experiments are listed in Table 1. Sample S4883 was synthesized from orthopyroxene loaded into a Re capsule in a Kawai-type multianvil press with a $\mathrm{LaCrO}_{3}$ heater assembly and $\mathrm{W}_{75} \mathrm{Re}_{25} / \mathrm{W}_{97} \mathrm{Re}_{03}$ thermocouple at $26 \mathrm{GPa}$ and $2000{ }^{\circ} \mathrm{C}$ for $40 \mathrm{~min}$ (Keppler and Frost 2005). The compositions of the starting materials were determined using the electron microprobe and conventional (radioactive point source) Mössbauer spectroscopy.

NIS measurements were made using panoramic DACs that were designed and constructed at Bayerisches Geoinstitut. For each experiment, a starting material in the form of powder was loaded into a Be gasket together with small ruby chips for pressure determination using the ruby scale of Mao et al. (1986). Generally, LiF or $\mathrm{NaCl}$ was used as a pressure medium. The diameters of the diamond culets and opening holes in the gaskets varied depending on the pressure range of the experiment. The samples were laser-heated in the DAC using a portable system mounted on the beamline incorporating either single-sided (Dubrovinsky et al. 2009) or doublesided (Kupenko et al. 2012) laser heating.

The NIS data were collected at ambient conditions on the nuclear resonance beamline ID18 at the European Synchrotron Radiation Facility (Rüffer and Chumakov 1996) between 2008 and 2010. Further details of the NIS setup and data analysis are given in Glazyrin et al. (2013) and references therein. Nuclear forward scattering (NFS) data were collected at the same time as the NIS data to monitor the electronic state of iron, and X-ray diffraction was used to confirm the identity of bridgmanite off-line after laser heating. The NIS data were collected typically over a range of -80 to $80 \mathrm{meV}$ around the ${ }^{57} \mathrm{Fe}$ nuclear resonance energy of $14.4 \mathrm{keV}$ in steps of $0.2 \mathrm{meV}$. The energy resolution of the $\mathrm{X}$-ray beam was $1 \mathrm{meV}$. Debye sound velocities $\left(V_{\mathrm{D}}\right)$ were determined from the reduced partial density of states (pDOS) using the "homogeneous model" described in Sinmyo et al. (2014). The densities required for the calculation of $V_{\mathrm{D}}$ of bridgmanite were determined using a third-order Birch-Murnaghan equation of state based on volumes and elastic parameters reported in Boffa Ballaran et al. (2012) (sample S4850) and Glazyrin et al. (2014) (samples U1219, SL16, SL18, S4883), where the generalized model in the latter work was used to calculate values relevant to the different compositions. Equations of state parameters for majorite were taken from McCammon and Ross (2003) (cell volume) and Kavner et al. (2000) (elastic parameters). The adiabatic bulk modulus can be used to calculate longitudinal wave $\left(\mathrm{V}_{\mathrm{P}}\right)$ and transverse wave $\left(\mathrm{V}_{\mathrm{S}}\right)$ velocities from $V_{\mathrm{D}}$ and vice versa (e.g., Sturhahn and Jackson 2007).

First-principles calculations were performed based on the local density approximation of DFT to determine the
DOS for $\mathrm{MgSiO}_{3}$ bridgmanite at $60 \mathrm{GPa}$ and antiferromagnetic $\mathrm{FeSiO}_{3}$ bridgmanite at 20, 40, and $60 \mathrm{GPa}$. We computed the dynamical matrices on a regular grid of $4 \times 4 \times 4$ special $q$ points (Monkhorst and Pack 1976) . We used Fourier interpolation techniques to obtain the interatomic force constants on a dense grid in the reciprocal space, from which we obtained the phonon DOS (Gonze et al. 2005). We determined both the total and

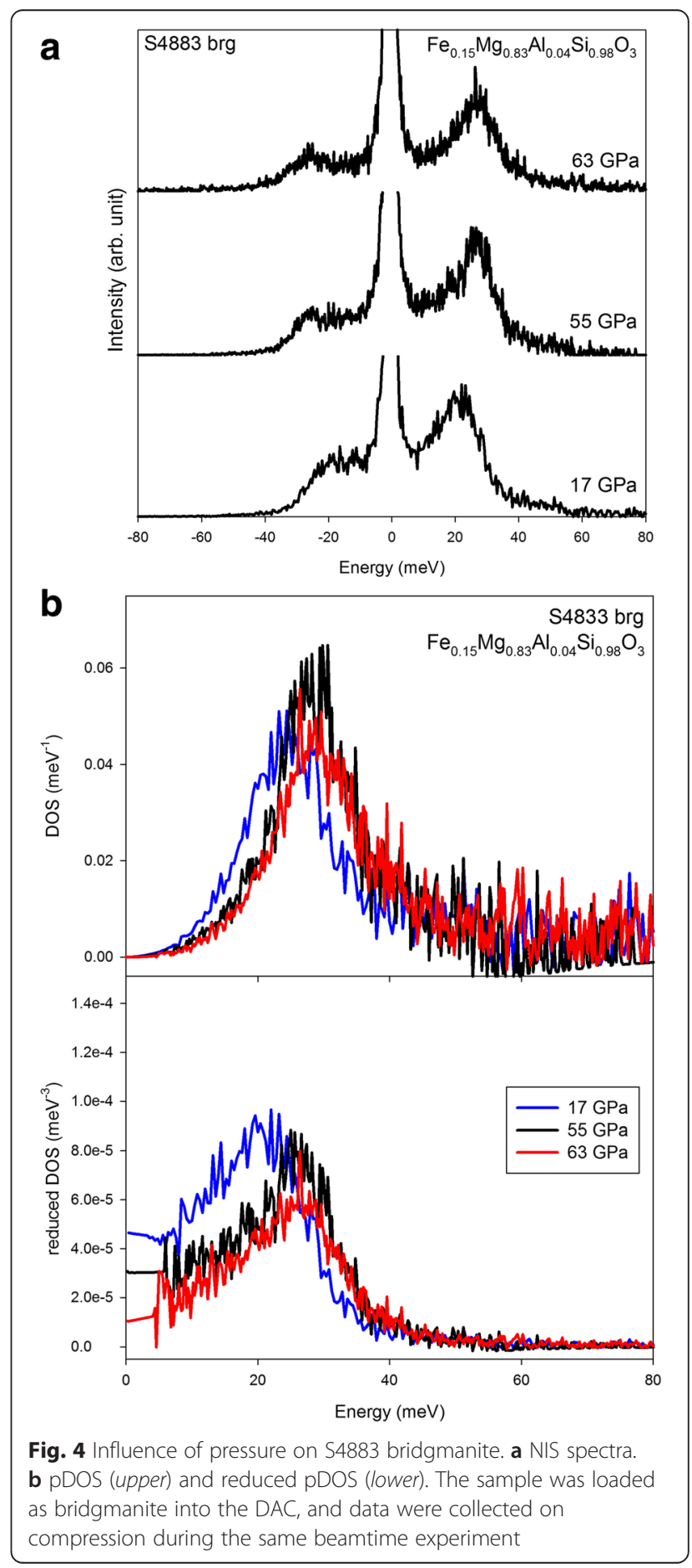



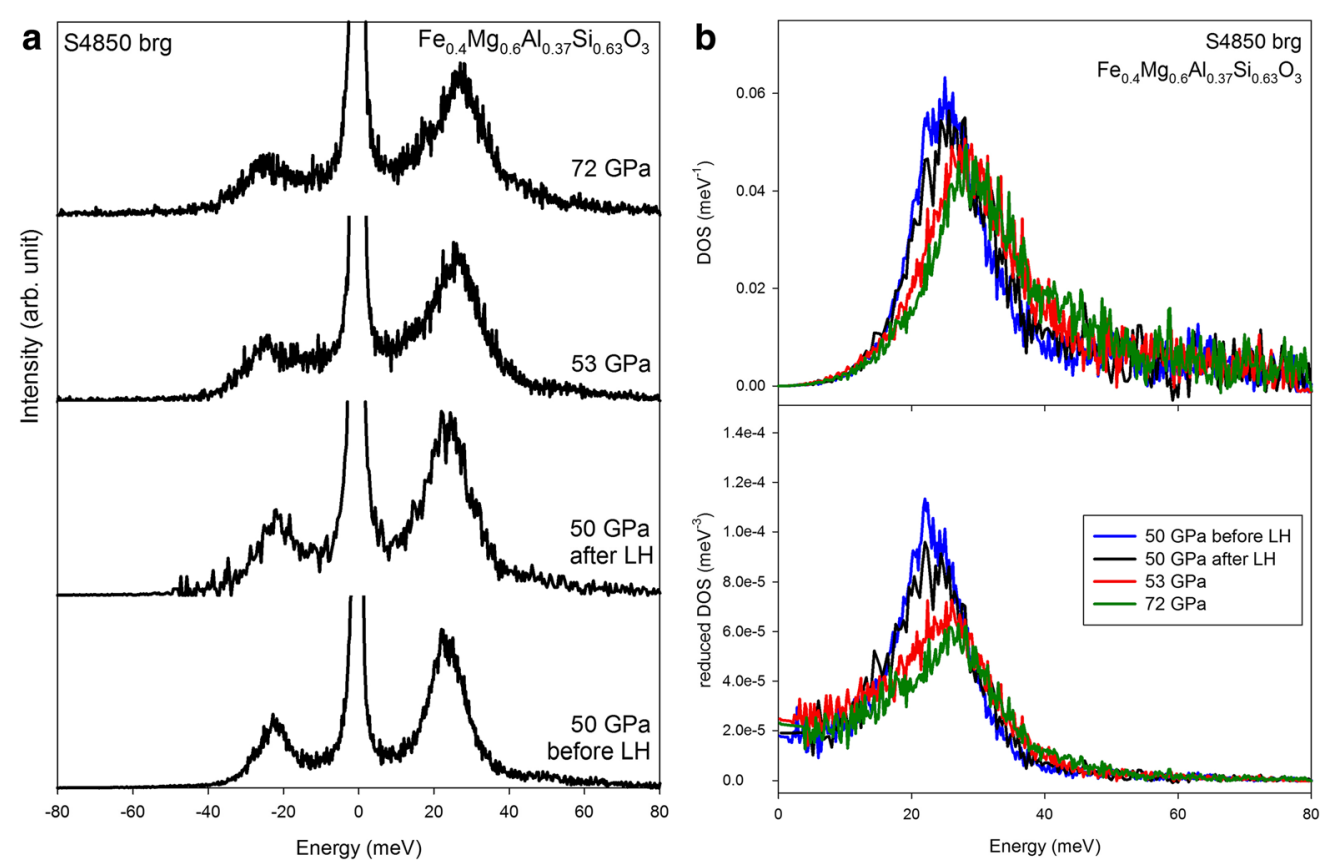

Fig. 5 Influence of pressure on 54850 bridgmanite. a NIS spectra. b pDOS (upper) and reduced pDOS (lower). The sample was loaded as bridgmanite into the DAC, and data were collected during two different beamtime experiments: \#1—50 GPa and \#2—53 and $72 \mathrm{GPa}$. The sample was laser-heated at $50 \mathrm{GPa}$, and data were collected both before and after laser heating
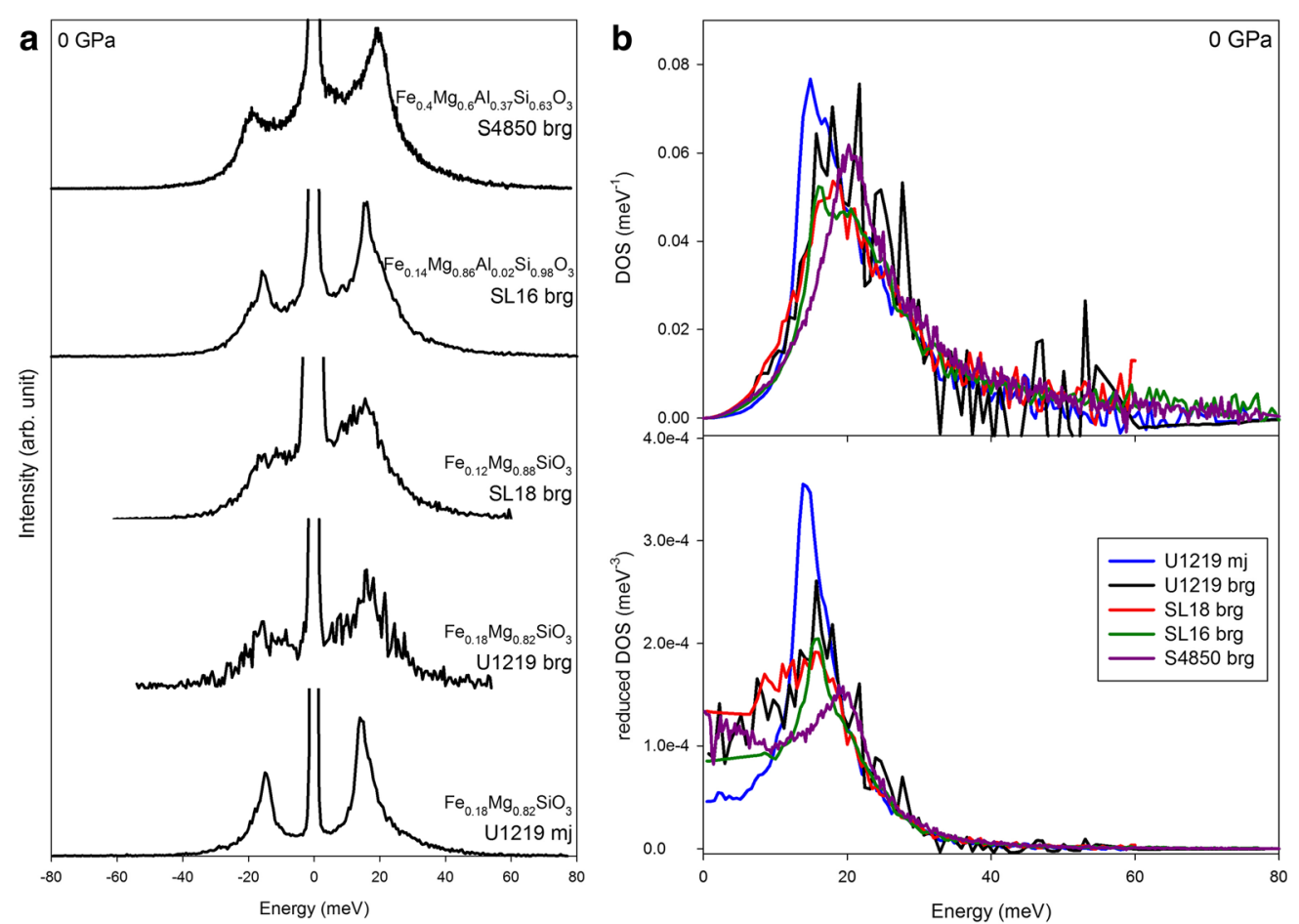

Fig. 6 Comparison of majorite and bridgmanite sample data at 0 GPa. a NIS spectra. b pDOS (upper) and reduced pDOS (Iower). Majorite was measured as the starting material in air while bridgmanite samples were measured after decompression 
Table 2 Debye sound velocities at high pressure determined from NIS at room temperature and DFT at $0 \mathrm{~K}$

\begin{tabular}{|c|c|c|c|c|c|c|c|}
\hline Sample & Phase & $\begin{array}{l}P \\
\mathrm{GPa}\end{array}$ & $\begin{array}{l}V_{D} \\
\mathrm{~km} / \mathrm{s}\end{array}$ & $\begin{array}{l}\sigma_{\mathrm{VD}} \\
\mathrm{km} / \mathrm{s}\end{array}$ & $\begin{array}{l}\rho \\
\mathrm{g} / \mathrm{cm}^{3}\end{array}$ & Method & Remarks \\
\hline U1219 & Majorite & 0 & 5.19 & 0.27 & 3.70 & NIS & Starting material \\
\hline U1219 & Majorite & 33 & 5.45 & 0.62 & 4.29 & NIS & \\
\hline U1219 & Bridgmanite & 0 & 3.56 & 0.46 & 4.31 & NIS & After decompression \\
\hline U1219 & Bridgmanite & 33 & 5.51 & 0.59 & 4.78 & NIS & \\
\hline U1219 & Bridgmanite & 41 & 5.80 & 0.66 & 4.87 & NIS & \\
\hline U1219 & Bridgmanite & 49 & 6.27 & 0.88 & 4.97 & NIS & \\
\hline U1219 & Bridgmanite & 62 & 5.62 & 0.55 & 5.11 & NIS & \\
\hline U1219 & Bridgmanite & 74 & 6.79 & 1.15 & 5.23 & NIS & \\
\hline U1219 & Bridgmanite & 89 & 7.23 & 1.17 & 5.37 & NIS & \\
\hline SL16 & Bridgmanite & 0 & 3.53 & 0.05 & 4.25 & NIS & Multianvil sample in air \\
\hline SL18 & Bridgmanite & 0 & 3.21 & 0.12 & 4.24 & NIS & After decompression \\
\hline SL18 & Bridgmanite & 0 & 3.97 & 0.15 & 4.24 & NIS & After decompression \\
\hline SL18 & Bridgmanite & 17 & 4.45 & 0.31 & 4.50 & NIS & \\
\hline SL18 & Bridgmanite & 36 & 5.72 & 0.38 & 4.74 & NIS & \\
\hline SL18 & Bridgmanite & 50 & 6.84 & 1.62 & 4.90 & NIS & \\
\hline SL18 & Bridgmanite & 62 & 5.95 & 0.31 & 5.03 & NIS & \\
\hline SL18 & Bridgmanite & 65 & 6.65 & 1.16 & 5.06 & NIS & \\
\hline SL18 & Bridgmanite & 75 & 6.47 & 1.15 & 5.16 & NIS & \\
\hline S4850 & Bridgmanite & 0 & 3.81 & 0.12 & 4.43 & NIS & After decompression \\
\hline S4850 & Bridgmanite & 50 & 6.95 & 1.26 & 5.15 & NIS & Before laser heating \\
\hline S4850 & Bridgmanite & 50 & 6.35 & 1.39 & 5.15 & NIS & After laser heating \\
\hline S4850 & Bridgmanite & 53 & 5.54 & 0.47 & 5.19 & NIS & \\
\hline S4850 & Bridgmanite & 72 & 6.14 & 0.69 & 5.40 & NIS & \\
\hline S4883 & Bridgmanite & 17 & 5.03 & 0.72 & 4.52 & NIS & \\
\hline S4883 & Bridgmanite & 55 & 5.11 & 0.53 & 4.99 & NIS & \\
\hline S4883 & Bridgmanite & 63 & 5.39 & 0.88 & 5.07 & NIS & \\
\hline $\mathrm{MgSiO}_{3}$ & Bridgmanite & 60 & 8.21 & 0.32 & 5.03 & DFT & From Mg partial DOS \\
\hline $\mathrm{FeSiO}_{3}$ & Bridgmanite & 60 & 6.73 & 0.22 & 6.22 & DFT & From Fe partial DOS \\
\hline
\end{tabular}

partial DOS for all the elements and calculated $V_{\mathrm{D}}$ using the same approach as for the experimental data. The equation of state parameters were taken from Caracas and Cohen (2005). We also determined seismic wave velocities from the full elastic tensor where elastic constants were obtained from the linear relation between stresses and strains. Uniaxial and/or pure shear strains on the order of $\pm 1 \%$ and $\pm 2 \%$ were applied, and then the positions of the atoms were relaxed. The elastic constants were determined from the residual stresses divided by the strains. Voigt-Reuss-Hill schemes were employed to average the elastic tensor, and seismic wave velocities were determined based on homogeneous aggregates.

\section{Results and discussion}

We measured room temperature NIS spectra of one majorite composition and five bridgmanite compositions

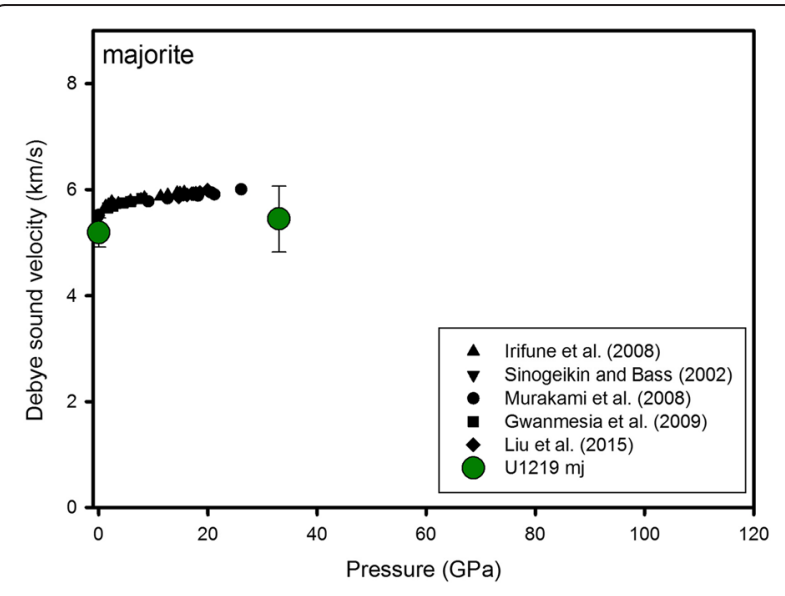

Fig. 7 Influence of pressure on $V_{D}$ for majorite. Values from the present study are indicated by large green circles, while literature data are indicated by black symbols according to the legend 


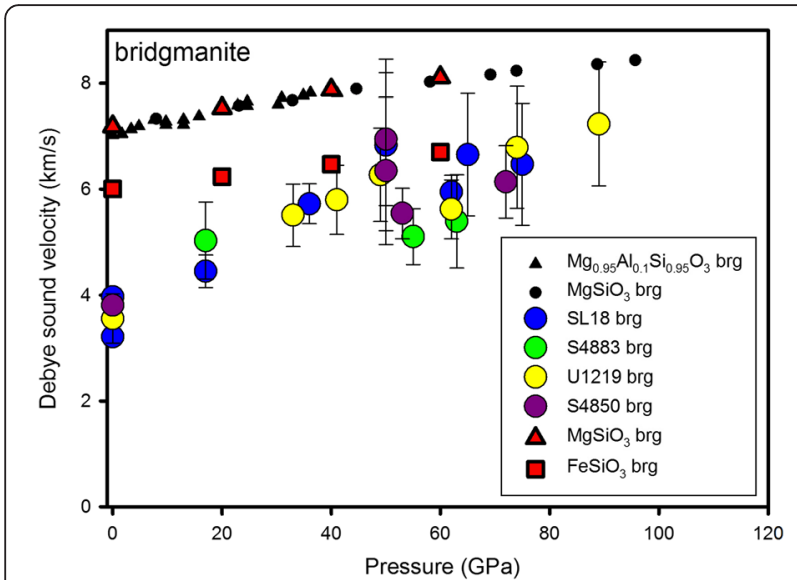

Fig. 8 Influence of pressure on $V_{D}$ for bridgmanite. Experimental values from the present study are indicated by large colored circles, while Brillouin scattering data from the literature are indicated by small black triangles (Jackson et al. 2005) and small black circles (Murakami et al. 2007). Values from a previous computational determination of the elastic tensor from finite differences (Caracas and Cohen 2005) are indicated as red triangles for $\mathrm{MgSiO}_{3}$ bridgmanite and red squares for antiferromagnetic $\mathrm{FeSiO}_{3}$ bridgmanite

as a function of pressure. In the case of majorite, sample U1219 was first measured at $33 \mathrm{GPa}$ and then laserheated to produce bridgmanite and measured again without changing pressure. The NIS spectra show a clear change between majorite and bridgmanite (Fig. 1a) that leads to different pDOS (Fig. 1b). Subsequent compression of the U1219 bridgmanite sample produced systematic changes in the NIS spectra (Fig. 2a) that are reflected in the pDOS (Fig. 2b). A similar behavior on compression was observed in bridgmanite with lower iron content (SL18, Fig. 3) and Al-containing bridgmanite with lower (S4883) and higher (S4850) amounts of $\mathrm{Fe}^{3+}$ (Figs. 4 and 5, respectively). Finally, we collected data for the five different samples at ambient conditions for comparison (Fig. 6).

Debye sound velocities $\left(V_{\mathrm{D}}\right)$ were calculated from the reduced DOS in the limit as energy goes to zero by averaging $\mathrm{D}(\mathrm{E}) / \mathrm{E}^{2}$ in the low-energy range as described in Sinmyo et al. (2014). $V_{\mathrm{D}}$ values for majorite (Table 2) are slightly lower than the results obtained for end-member $\mathrm{MgSiO}_{3}$ majorite and solid solutions containing $\mathrm{Fe}$ and/or $\mathrm{Al}$ that were obtained using ultrasonics $\left(\mathrm{Mg}_{0.59} \mathrm{Fe}_{0.04} \mathrm{Ca}_{0.18} \mathrm{Na}_{0.03} \mathrm{Al}_{0.23} \mathrm{Cr}_{0.01}\right.$ $\mathrm{Si}_{0.90} \mathrm{O}_{3}$ : Irifune et al. 2008; $\mathrm{Mg}_{0.875} \mathrm{Al}_{0.25} \mathrm{Si}_{0.875} \mathrm{O}_{3}$ and $\mathrm{Mg}_{0.85} \mathrm{Al}_{0.3} \mathrm{Si}_{0.85} \mathrm{O}_{3}$ : Gwanmesia et al. 2009; $\mathrm{Mg}_{0.95} \mathrm{Al}_{0.1} \mathrm{Si}_{0.95} \mathrm{O}_{3}$ : Liu et al. 2015) and Brillouin scattering $\left(\mathrm{MgSiO}_{3}\right.$ and $\mathrm{Mg}_{0.875} \mathrm{Al}_{0.25} \mathrm{Si}_{0.875} \mathrm{O}_{3}$ : Sinogeikin and Bass 2002, $\mathrm{Mg}_{0.79} \mathrm{Fe}_{0.08} \mathrm{Al}_{0.30} \mathrm{Si}_{0.84} \mathrm{O}_{3}$ : Murakami et al. 2008) (Fig. 7). These lower values are consistent with the higher iron content of our majorite $\left(\mathrm{Mg}_{0.82} \mathrm{Fe}_{0.18} \mathrm{SiO}_{3}\right)$. In contrast, the $V_{\mathrm{D}}$ values for bridgmanite (Table 2) are unrealistically low compared to the results from Brillouin scattering (Fig. 8). We can rule out the influence of local clustering as a significant factor that lowers velocities

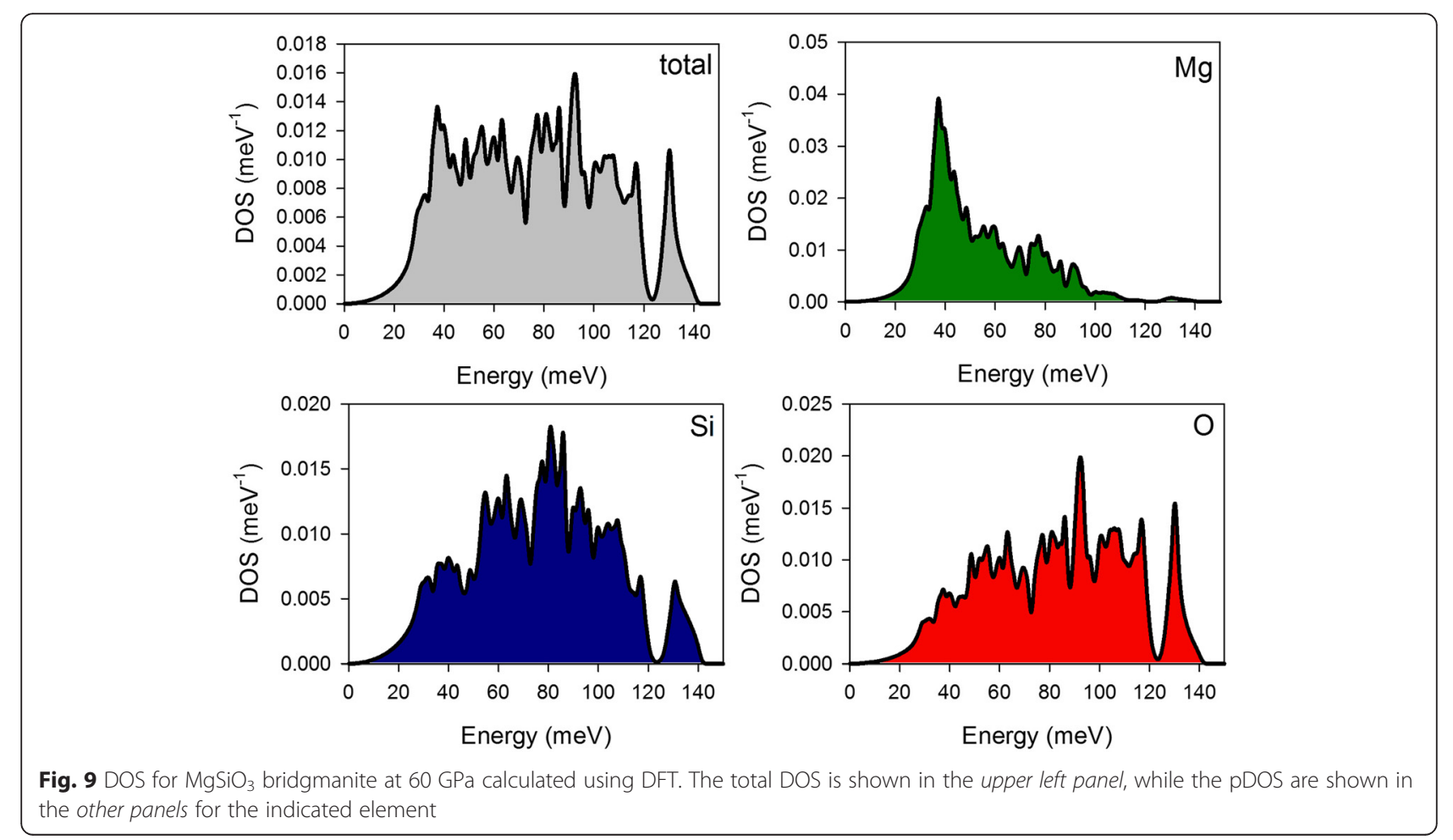



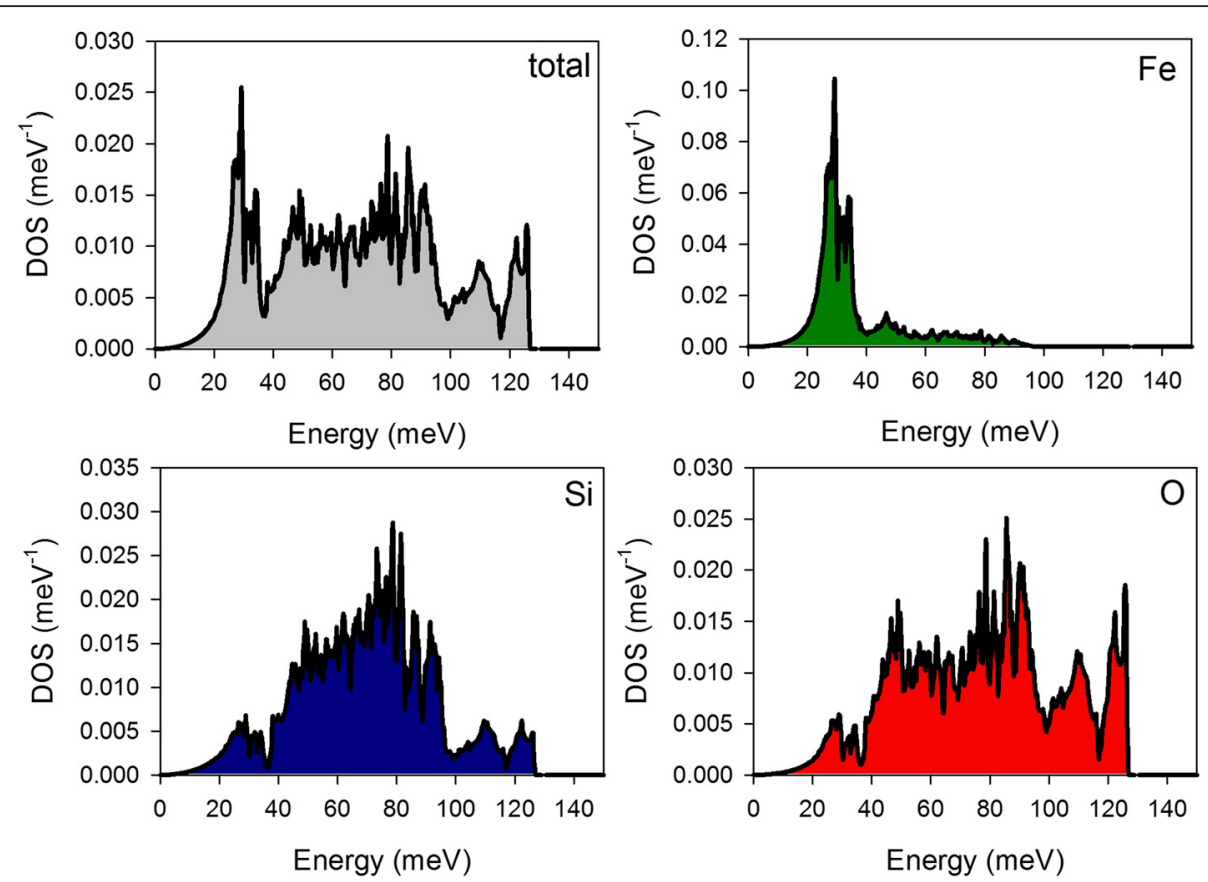

Fig. $10 \mathrm{DOS}$ for antiferromagnetic $\mathrm{FeSiO}_{3}$ bridgmanite at $60 \mathrm{GPa}$ calculated using DFT. The total DOS is shown in the upper left panel, while the pDOS are shown in the other panels for the indicated element

since the effect is too small to account for the large discrepancy (e.g., Sinmyo et al. 2014).

For a better understanding of the DOS for end-member bridgmanite, we calculated the total DOS for $\mathrm{MgSiO}_{3}$ bridgmanite and antiferromagnetic $\mathrm{FeSiO}_{3}$ bridgmanite as well as the pDOS for each element at $60 \mathrm{GPa}$ (Figs. 9 and 10). For consistency with previous finite difference computations (Caracas and Cohen 2005), we calculated the full elastic tensor to confirm that we obtained the same elastic velocities within error. We then applied the same approach used to obtain $V_{\mathrm{D}}$ from the experimental DOS obtained from NIS data to the theoretical DOS shown in Figs. 9 and 10. We found that the $V_{\mathrm{D}}$ values calculated from each pDOS as well as the total DOS for each phase were identical within error, i.e., the same result is obtained irrespective of which element pDOS is used. In addition, we found that the $V_{\mathrm{D}}$ values calculated using this approach (Table 2) are consistent with values that we obtained from the full elastic tensor $(8.23$ and $6.78 \mathrm{~km} / \mathrm{s}$ for $\mathrm{MgSiO}_{3}$ and $\mathrm{FeSiO}_{3}$, respectively).

A Birch plot for bridgmanite data from both calculations and experiments highlights the anomalous behavior of sound velocities determined using NIS (Fig. 11). To obtain further insight into the origin of the low velocities of bridgmanite, we compare the pDOS for experiments and calculations. The breadth of vibrational states is smaller for bridgmanite calculated at $0 \mathrm{~K}$ compared to the experimental data at room temperature, but it is similar for the experimental data for both bridgmanite and majorite at room temperature (Fig. 12, upper). In the reduced pDOS, the enhanced intensity at low energies in the experimental bridgmanite data leads to a significantly higher intercept and hence lower velocity compared to both calculated bridgmanite and experimental majorite (Fig. 12, lower). While particle size (e.g., Marquardt et al. 2011) or anisotropy (Chumakov et al. 2009) could be a factor, we note that this effect is present in all the bridgmanite compositions that we measured using NIS, irrespective of sample synthesis method or history (i.e., whether they were

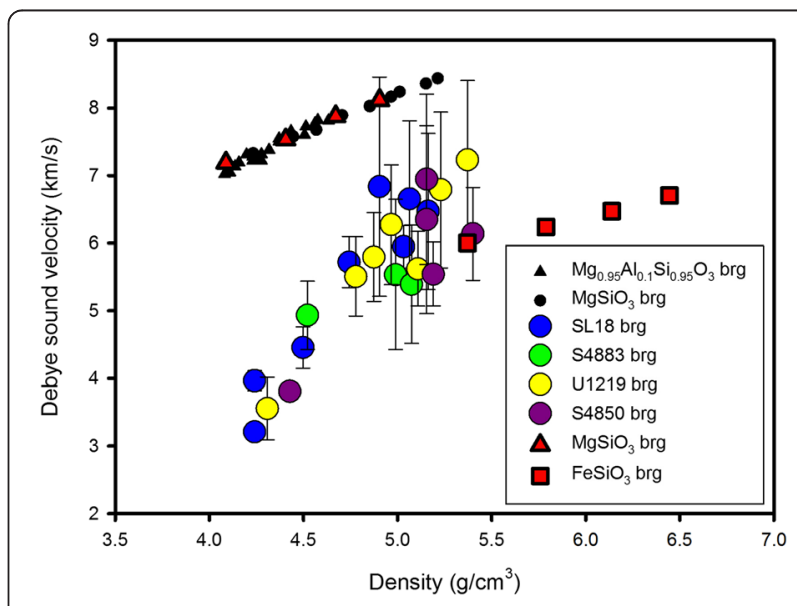

Fig. 11 Birch plot of $V_{D}$ versus density for bridgmanite. Symbols are the same as for Fig. 8 


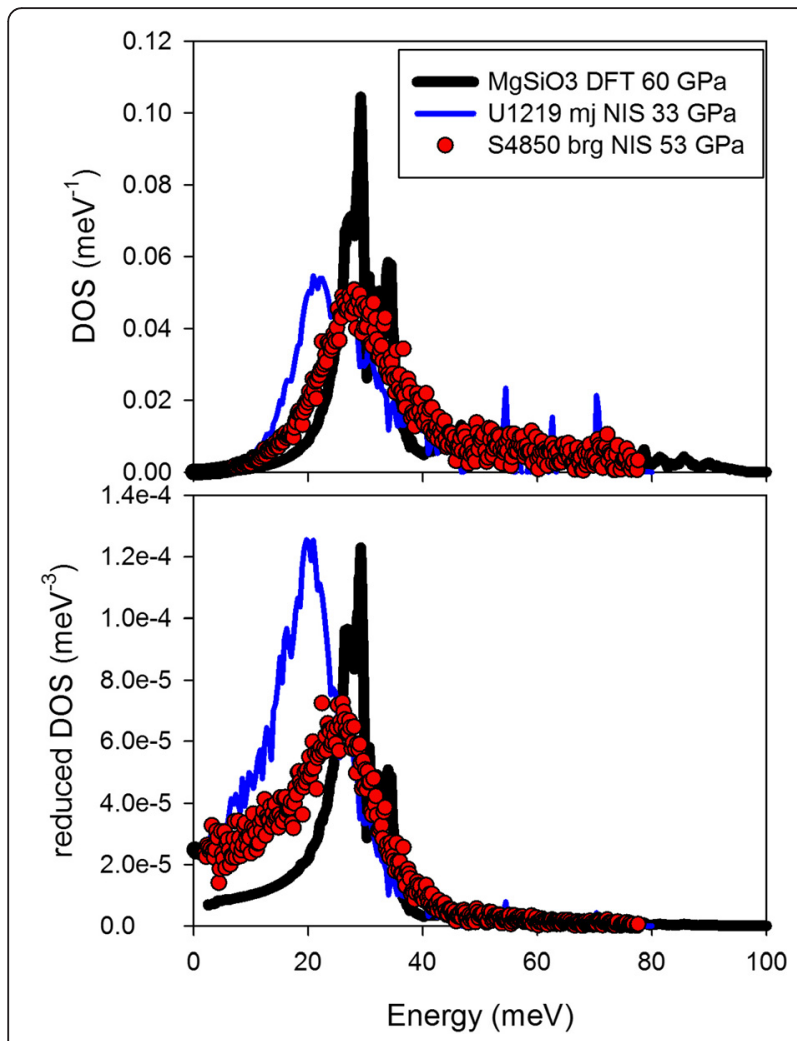

Fig. 12 Comparison of pDOS (upper) and reduced pDOS (lower) determined by experiment and calculation. Experimental data are from the room temperature NIS spectra of $\$ 4850$ bridgmanite at $53 \mathrm{GPa}$ (red circles) and U1219 majorite at $33 \mathrm{GPa}$ (blue line) while the black line indicates DFT calculations of antiferromagnetic $\mathrm{FeSiO}_{3}$ bridgmanite at $60 \mathrm{GPa}$ and $0 \mathrm{~K}$

synthesized in the multianvil press or by laser heating in the DAC). While it is clear from our results that sound velocities for bridgmanite determined using NIS cannot be used for comparison with seismic data, there is clearly scope for further work to identify the contributions to the vibrational DOS derived from NIS data in order to more fully understand the lattice vibrational properties of bridgmanite.

\section{Conclusions}

Our work has presented an extensive dataset for bridgmanite with different compositions based on NIS measurements in a DAC as well as first-principles calculations:

(1) NIS measurements of majorite give sound velocities that are consistent with literature data from other methods, while NIS measurements of bridgmanite give sound velocities that are significantly lower than literature data.

(2) Sound velocities of bridgmanite determined from NIS data are consistently low, irrespective of composition or sample history.
(3) Treatment of the DOS calculated using DFT for $\mathrm{MgSiO}_{3}$ and $\mathrm{FeSiO}_{3}$ bridgmanite using the same approach as for the NIS data gives sound velocities that are consistent with each other for each phase irrespective of which partial DOS is used.

(4) Treatment of the DOS calculated using DFT for $\mathrm{MgSiO}_{3}$ and $\mathrm{FeSiO}_{3}$ bridgmanite using the same approach as for the NIS data gives sound velocities that are consistent with the values obtained from the calculation of the full elastic tensor.

(5) Comparison of the calculated and experimental DOS shows enhanced intensity at low energies in the latter that leads to the lower sound velocities.

\section{Abbreviations \\ DAC: diamond anvil cell; DFT: density functional theory; DOS: density of states; NFS: nuclear forward scattering; NIS: nuclear inelastic scattering; pDOS: partial density of states.}

\section{Competing interests}

The authors declare that they have no competing interests.

\section{Authors' contributions}

$C M, R C$, and LD proposed the topic and conceived and designed the study. The experimental data were collected by $C M, K G, V P, A K, R S, C P, I K, A C$, and LD. CM, KG, CP, and AC analyzed the experimental data, and RC carried out the ab initio calculations. All authors provided input to the interpretation of the data and the writing of the manuscript. All authors read and approved the final manuscript.

\section{Acknowledgements}

We acknowledge the European Synchrotron Radiation Facility for the provision of synchrotron radiation facilities (ID18), and we would like to thank $R$ Rüffer and J-P Celse for additional assistance. The project was supported by funds from the German Science Foundation (DFG) in their normal funding program and Priority Program SPP1236, the PROCOPE exchange program, and the German Federal Ministry for Education and Research (BMBF). RS was supported by a Research Fellowship for Postdoctoral Researchers awarded by the Alexander von Humboldt Foundation.

\section{Author details}

'Bayerisches Geoinstitut, Universität Bayreuth, Bayreuth 95440, Germany. ¿Laboratoire de Géologie de Lyon UMR CNRS 5276, Ecole Normale Supérieure de Lyon, Lyon Cedex 07 69364, France. ${ }^{3}$ Deutsches Elektronen-Synchrotron, Hamburg 22607, Germany. ${ }^{4}$ European Synchrotron Radiation Facility, Grenoble Cedex 9 38043, France. ${ }^{5}$ National Research Center "Kurchatov Institute", Moscow 123182, Russia. 'ELSI, Tokyo Institute of Technology, Tokyo 152-8550, Japan. ${ }^{7}$ Institut für Geologie und Mineralogie, Universität zu Köln, Köln 50969, Germany. ${ }^{8}$ Institut für Mineralogie, Universität Münster, Münster 48149, Germany.

Received: 30 November 2015 Accepted: 19 April 2016

Published online: 28 April 2016

\section{References}

Birch F (1952) Elasticity and constitution of the Earth's interior. J Geophys Res 57: 227-286

Boffa Ballaran T, Kurnosov A, Glazyrin K, Frost DJ, Merlini M, Hanfland M, Caracas $R$ (2012) Effect of chemistry on the compressibility of silicate perovskite in the lower mantle. Earth Planet Sci Lett 333-334:181-190

Caracas R, Cohen RE (2005) Effect of chemistry on the stability and elasticity of the perovskite and post-perovskite phases in the $\mathrm{MgSiO}_{3}-\mathrm{FeSiO}_{3}-\mathrm{Al}_{2} \mathrm{O}_{3}$ system and implications for the lowermost mantle. Geophys Res Lett 32: L16310. doi:10.1029/2005GL023164 
Chen B, Jackson JM, Sturhahn W, Zhang D, Zhao J, Wicks JK, Murphy CA (2012) Spin crossover equation of state and sound velocities of $\left(\mathrm{Mg}_{0.65} \mathrm{Fe}_{0.35}\right) \mathrm{O}$ ferropericlase to 140 GPa. J Geophys Res 117(B08208):2012. doi:10.1029/ $2012 J B 009162$

Chumakov Al, Bosak A, Rüffer R (2009) Contribution of acoustic modes to the density of vibrational states measured by inelastic scattering techniques. Phys Rev B 90(094303):1-8

Crowhurst JC, Brown JM, Goncharov AF, Jacobsen SD (2008) Elasticity of (Mg, $\mathrm{Fe}) \mathrm{O}$ through the spin transition of iron in the lower mantle. Science 319: $451-453$

Dubrovinsky L, Glazyrin K, McCammon C, Narygina O, Greenberg E, Übelhack S, Chumakov Al, Pascarelli S, Prakapenka V, Bock J, Dubrovinskaia N (2009) Portable laser-heating system for diamond anvil cells. J Synchrotron Radiat 16:737-741

Fiquet G, Badro J, Guyot F, Bellin C, Krisch M, Antonangeli D, Requardt H, Mermet A, Farber D, Aracne-Ruddle C, Zhang J (2004) Application of inelastic X-ray scattering to the measurements of acoustic wave velocities in geophysical materials at very high pressure. Phys Earth Planet Int 143-144:5-18

Glazyrin K, Pourovskii LV, Dubrovinsky L, Narygina O, McCammon C, Hewener B, Schünemann V, Wolny J, Muffler K, Chumakov Al, Crichton W, Hanfland M, Prakapenka V, Tasnádi F, Ekholm M, Aichhorn M, Vildosola V, Ruban AV, Katsnelson MI, Abrikosov IA (2013) Importance of correlation effects in hcp iron revealed by a pressure-induced electronic topological transition. Phys Rev Lett 110:117206

Glazyrin K, Boffa Ballaran T, Frost DJ, McCammon C, Kantor A, Merlini M, Hanfland M, Dubrovinsky L (2014) Effect of iron oxidation state on the bulk sound velocity of the Earth's lower mantle. Earth Planet Sci Lett 393:182-186

Gonze X, Rignanese G-M, Caracas R (2005) First-principles studies of the lattice dynamics of crystals, and related properties. Z Krist 220:458-472

Gwanmesia GD, Wang L, Triplett R, Liebermann RC (2009) Pressure and temperature dependence of the elasticity of pyrope-majorite [Py60Mj40 and Py50Mj50] garnets solid solution measured by ultrasonic interferometry technique. Phys Earth Planet In 174:105-112

Irifune T, Higo Y, Inoue T, Kono Y, Ohfuji H, Funakoshi K (2008) Sound velocities of majorite garnet and the composition of the mantle transition region. Nature 451:814-817

Jackson JM, Zhang J, Shu J, Sinogeikin SV, Bass JD (2005) High-pressure sound velocities and elasticity of aluminous $\mathrm{MgSiO}_{3}$ perovskite to $45 \mathrm{GPa}$ : implications for lateral heterogeneity in Earth's lower mantle. Geophys Res Lett 32, doi:10.1029/2005GL023522, 022005

Jackson JM, Hamecher EA, Sturhahn W (2009) Nuclear resonant X-ray spectroscopy of (Mg, Fe)SiO3 orthoenstatites. Eur J Mineral 21:551-560

Kavner A, Sinogeikin SV, Jeanloz R, Bass JD (2000) Equation of state and strength of natural majorite. J Geophys Res 105(B3):5963-5971

Keppler H, Frost DJ (2005) Introduction to minerals under extreme conditions. In: Miletich R (ed) Mineral behaviour at extreme conditions, vol 7, EMU notes in mineralogy. Eötvös University Press, Budapest, pp 1-30

Kupenko I, Dubrovinsky L, Dubrovinkskaya N, McCammon C, Glazyrin K, Bykova E, Boffa Ballaran T, Sinmyo R, Chumakov Al, Potapkin V, Kantor A, Rüffer R, Hanfland M, Crichton W, Merlini M (2012) Portable double-sided laserheating system for energy-domain Mössbauer spectroscopy and single crystal X-ray diffraction experiments at synchrotron facilities with diamond anvil cells. Rev Sci Instrum 83:124501

Lauterbach S (2000) Der Oxidationsgrad des Eisens im unteren Mantel: Eine Studie des $\mathrm{Fe}^{3+}$-Gehaltes des Silikat-Perowskits in Abhängigkeit seines AlGehaltes mit Mössbauer-Spektroskopie und Elektronen-Energie-VerlustSpektroskopie (EELS). University of Bayreuth, Dissertation

Lauterbach S, McCammon CA, van Aken P, Langenhorst F, Seifert F (2000) Mössbauer and ELNES spectroscopy of (Mg, Fe)(Si, Al)O3 perovskite: a highly oxidised component of the lower mantle. Contrib Mineral Petrol 138:17-26

Lin J-F, Jacobsen SD, Sturhahn W, Jackson JM, Zhao J, Yoo C-S (2006) Sound velocities of ferropericlase in the Earth's lower mantle. Geophys Res Lett 33, doi:10.1029/2006GL028099, 022006

Liu Z, Irifune T, Gréaux S, Arimoto T, Shinmei T, Higo Y (2015) Elastic wave velocity of polycrystalline Mj80Py20 garnet to $21 \mathrm{GPa}$ and 2,000 K. Phys Chem Miner 42:213-222

Mao H-K, Xu J-A, Bell PM (1986) Calibration of the ruby pressure gauge to 800 kbar under quasi-hydrostatic conditions. J Geophys Res 91:4673-4676

Mao WL, Mao H-K, Sturhahn W, Zhao J, Prakapenka VB, Meng Y, Shu J, Fei Y, Hemley RJ (2006) Iron-rich post-perovskite and the origin of ultralow-velocity zones. Science 312:564-565
Marquardt H, Gleason A, Marquardt K, Speziale S, Miyagi L, Neusser G, Wenk H-R, Jeanloz R (2011) Elastic properties of MgO nanocrystals and grain boundaries at high pressures by Brillouin scattering. Phys Rev B 84(064131):1-9

McCammon CA, Ross NL (2003) Crystal chemistry of ferric iron in (Mg, Fe)(Si, Al)O3 majorite with implications for the transition zone. Phys Chem Minerals 30:206-216

McCammon C, Kantor I, Narygina O, Rouquette J, Ponkratz U, Sergueev I, Mezouar M, Prakapenka V, Dubrovinsky L (2008) Stable intermediate-spin ferrous iron in lower mantle perovskite. Nat Geosci 1:684-687

McCammon C, Dubrovinsky L, Narygina O, Kantor I, Wu X, Glazyrin K, Sergueev I, Chumakov A (2010) Low-spin $\mathrm{Fe}^{2+}$ in silicate perovskite and a possible layer at the base of the lower mantle. Phys Earth Planet Int 180:215-221

McCammon C, Glazyrin K, Kantor A, Kantor I, Kupenko I, Narygina O, Potapkin V, Prescher C, Sinmyo R, Chumakov A, Rüffer R, Sergueev I, Smirnov G, Dubrovinsky L (2013) Iron spin state in silicate perovskite at conditions of the Earth's deep interior. High Pressure Res 33:663-672

Monkhorst HJ, Pack JD (1976) Special points for Brillouin-zone integrations. Phys Rev B 13:5188-5192

Murakami M, Sinogeikin SV, Hellwig H, Bass JD, Li J (2007) Sound velocity of $\mathrm{MgSiO}_{3}$ perovskite to Mbar pressure. Earth Planet Sci Lett 256:47-54

Murakami M, Sinogeikin SV, Litasov K, Ohtani E, Bass JD (2008) Single-crystal elasticity of iron-bearing majorite to $26 \mathrm{GPa}$ : implications for seismic velocity structure of the mantle transition zone. Earth Planet Sci Lett 274:339-345

Potapkin V, McCammon C, Glazyrin K, Kantor A, Kupenko I, Prescher C, Sinmyo R, Smirnov GV, Chumakov Al, Rüffer R, Dubrovinsky L (2013) Effect of iron oxidation state on the electrical conductivity of the Earth's lower mantle. Nat Commun 4(1427):1-6

Rüffer R, Chumakov Al (1996) Nuclear resonance beamline at ESRF. Hyperfine Interact 97(98):589-604

Shukla G, Wu Z, Hsu H, Floris A, Cococcioni M, Wentzcovitch RM (2015) Thermoelasticity of $\mathrm{Fe}^{2+}$-bearing bridgmanite. Geophys Res Lett 42: $1741-1749$

Sinmyo R, Glazyrin K, McCammon C, Kupenko I, Kantor A, Potapkin V, Chumakov Al, Rüffer R, Dubrovinsky $L$ (2014) The influence of solid solution on elastic wave velocity determination in (Mg, Fe)O using nuclear inelastic scattering. Phys Earth Planet Int 229:16-23

Sinogeikin SV, Bass JD (2002) Elasticity of majorite and a majorite-pyrope solid solution to high pressure: implications for the transition zone. Geophys Res Lett 29:10.1029/2001GL013937

Stackhouse S (2008) The spin deep within. Nat Geosci 1:648-650

Sturhahn W, Jackson JM (2007) Geophysical applications of nuclear resonant spectroscopy. In: Ohtani E (ed) Advances in high-pressure mineralogy, GSA special paper 421. Geological Society of America, Boulder, pp 157-174

Townsend JP, Tsuchiya J, Bina CR, Jacobsen SD (2015) First-principles investigation of hydrous post-perovskite. Phys Earth Planet In 244:42-48

Wang X, Tsuchiya T, Hase A (2015) Computational support for a pyrolitic lower mantle containing ferric iron. Nat Geosci 8:556-559

Wicks JK, Jackson JM, Sturhahn W (2010) Very low sound velocities in iron-rich (Mg,Fe)O: implications for the core-mantle boundary region. Geophys Res Lett 37:L15304. doi:10.1029/2010GL043689

\section{Submit your manuscript to a SpringerOpen ${ }^{\circ}$ journal and benefit from:}

- Convenient online submission

- Rigorous peer review

- Immediate publication on acceptance

- Open access: articles freely available online

- High visibility within the field

- Retaining the copyright to your article

Submit your next manuscript at springeropen.com 